\title{
Article \\ Stiffness of the Masseter Muscle in Children-Establishing the Reference Values in the Pediatric Population Using Shear-Wave Elastography
}

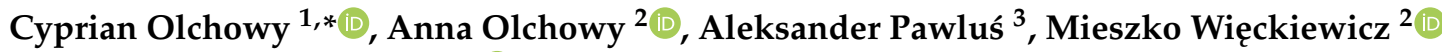 \\ and Luca Maria Sconfienza 4,5 (D) \\ 1 Department of Oral Surgery, Wroclaw Medical University, 50-425 Wroclaw, Poland \\ 2 Department of Experimental Dentistry, Wroclaw Medical University, 50-425 Wroclaw, Poland; \\ ania.olchowy@gmail.com (A.O.); m.wieckiewicz@onet.pl (M.W.) \\ 3 Department of General Radiology, Provincial Specialist Hospital in Legnica, 59-220 Legnica, Poland; \\ apawlus@wp.pl \\ 4 Unità Operativa di Radiologia Diagnostica e Interventistica, IRCCS Istituto Ortopedico Galeazzi, \\ 20161 Milano, Italy; io@lucasconfienza.it \\ 5 Dipartimento di Scienze Biomediche per la Salute, Università degli Studi di Milano, 20161 Milano, Italy \\ * Correspondence: cyprian.olchowy@gmail.com
}

Citation: Olchowy, C.; Olchowy, A.; Pawluś, A.; Więckiewicz, M.; Sconfienza, L.M. Stiffness of the Masseter Muscle in ChildrenEstablishing the Reference Values in the Pediatric Population Using Shear-Wave Elastography. Int. J. Environ. Res. Public Health 2021, 18, 9619. https://doi.org/10.3390/ ijerph18189619

Academic Editor:

José Carmelo Adsuar Sala

Received: 17 July 2021

Accepted: 9 September 2021

Published: 13 September 2021

Publisher's Note: MDPI stays neutral with regard to jurisdictional claims in published maps and institutional affiliations.

Copyright: (c) 2021 by the authors. Licensee MDPI, Basel, Switzerland. This article is an open access article distributed under the terms and conditions of the Creative Commons Attribution (CC BY) license (https:/ / creativecommons.org/licenses/by/ $4.0 /)$.

\begin{abstract}
In children, the quality and muscle function are altered in many pathologic conditions, including temporomandibular disorders. Although several methods have been used to evaluate muscle tonus, none became a golden standard. Moreover, the masseter muscle characteristics in children have not been investigated to date. This study aimed to measure the stiffness of the masseter muscle using shear-wave elastography in healthy children. We enrolled 30 healthy children (mean age $10.87 \pm 3.38$ years). The stiffness of masseter muscles was measured with shear wave elastography. Stiffness for the total sample was $6.37 \pm 0.77 \mathrm{kPa}$. A comparison of the measurements did not show significant differences between the right and the left masseter muscles (left-6.47 $\pm 0.78 \mathrm{kPa}$; right $-6.24 \pm 0.76 \mathrm{kPa} ; p=0.3546$ ). A significant difference was seen between boys and girls (boys$5.94 \pm 0.50 \mathrm{kPa}$; girls $-6.63 \pm 0.80 ; p=0.0006)$. Shear-wave elastography is a promising diagnostic tool. It may help to detect changes in the stiffness of the masseter muscle and draw attention to pathological processes within the jaw muscles. Directions for further research shall include determining stiffness values in pathological conditions and the impact of biological and functional factors on the stiffness of the masseter muscle.
\end{abstract}

Keywords: shear-wave elastography; masseter; temporomandibular disorders; elasticity; pediatric population

\section{Introduction}

The quality and muscle function are altered in many pathologic conditions. In children, disturbed muscle functioning can be associated with hereditary diseases (muscular and neuromuscular dystrophies) [1], injuries to the brain resulting in cerebral palsy [2], juvenile idiopathic arthritis [3], locomotor system disabilities [4] and temporomandibular disorders (TMD) [5]. It has been estimated that atypical muscle tone affects about $5-8 \%$ of children [6]; however, local changes in the muscle tone may be more frequent.

TMD is an umbrella term that embraces chronic pain conditions and dysfunction in the orofacial region affecting the masticatory muscles, the temporomandibular joints and their associated structures. TMD are often associated with pain that can have muscle origin $[7,8]$. The prevalence of TMD in the general adult population in Poland is estimated to be as high as 55.9\% [9]. Such data are not available in the population of Polish children and adolescents, but the available studies on other country populations indicate that TMD prevalence in children and adolescents range from $7.3 \%$ to $30.4 \%[10,11]$, although the 
prevalence of TMD in adolescents can be even as high as 33\% as highlighted by the study conducted in Brazil [12]. The prevalence of TMD is believed to increase with age [13].

Methods of assessing muscle condition help monitor the progression of the disease and the evaluation of implemented treatment. Some attempts were reported on the use of myotonometry to evaluate muscle stiffness both in healthy people and children with Duchenne muscular dystrophy $[14,15]$. Surface electromyography, used for the measurement of muscle activity, can also help evaluate a muscle condition in children with cerebral palsy [16]. In addition, it was shown that in children with TMD, electromyography was able to detect the lower activity of the masseter muscle in comparison with children without abnormalities in this muscle [17]. It is worth noting that biomechanical methods lack standardization. They are characterized by high variability, which hampers comparisons between individuals and the conduct of clinical research [16]. In addition to biomechanical methods, several clinical scales are used (e.g., Ashworth Scale) [18] to assess muscle tone, but there is no agreement among clinicians on the gold standard. Finally, there is no method for the routine assessment of hypotonia [19].

Shear-wave elastography is gaining attention in recent years. This method was validated in studies with phantoms of known hardness and comparative studies [20,21]. The results of studies on internal organs such as the thyroid, kidneys or liver, show that the agreement between the radiologists is statistically significant [22-24]. There are also some attempts to use shear-wave elastography for measuring muscle stiffness. Goo et al. conducted a systematic review to identify methods used for the evaluation of skeletal muscle mechanical properties in the pediatric population [6]. They identified 60 studies with data published in 40 articles on the shear-wave elastography conducted with Aixplorer (Supersonic Imagine, France). They concluded that this method was characterized by strong $(+++)$ intra-rater, inter-rater and test-retest reliability. In the literature, shear-wave elastography was used to measure spasticity in children with cerebral palsy [25], Duchenne muscular dystrophy [26] and muscle condition in scoliosis [27]. The examined muscles included gastrocnemius muscle [25], tibialis anterior [26], vastus lateralis [26], biceps brachii [26], triceps brachii [26], adductor digitorum minimi [26] and lateral abdominal muscle [27]. Another advantage of shear-wave elastography is its ability to identify trigger points and help to make a diagnosis of myofascial pain syndrome [28]. Among other advantages of shear-wave elastography, it is its simplicity that allows dentists and other specialists to monitor disease response to treatment [29].

The assessment of masticatory muscles would be useful in the treatment of TMD and other pathologies generally affecting muscle condition; however, the masseter muscle characteristics in children have not been investigated to date. For this reason, the aim of this study was to measure the stiffness of the masseter muscle using shear-wave elastography in healthy children.

\section{Materials and Methods}

This study included 30 healthy children, namely older than one year of age and younger than 18 years of age. We aimed to include healthy children in terms of the lack of any systemic and oral disease or pathologic condition. Subjects with symptoms or a history of any disease that affects muscle tonus, including neuromuscular disorders, cancer, symptoms of TMD, oral parafunctions and orofacial pain, were not considered. In addition, patients who were taking muscle relaxants, other drugs affecting the muscles, analgesics and botulin injections in the examined area were not included. Parents were asked for written informed consent for the participation of their child in the study. All children gave their consent for participation in the study as well. The study was approved by the Bioethical Committee at the Wroclaw Medical University (KB-633/2020). The study was conducted in accordance with the Declaration of Helsinki and Good Clinical Practice.

Stiffness of masseter muscles was measured with shear wave elastography using Aixplorer Ultimate device (SuperSonic Imagine, Aix-en-Provence, France) with a highfrequency linear probe SL 18-5 (5-18 MHz). All children were examined in a supine; they 
were instructed to lay down relaxed with their mouth closed in a comfortable position as well as to refrain from swallowing during the examination. A small amount of an ultrasound gel was used for better visualization. The probe was placed longitudinally to the long axis of the masseter muscle. The measurements were registered in the widest and thickest part of the muscle belly-half-length in between the origin and insertion of the masseter muscle [30,31]. The Region of Interest (ROI) diameter of $4 \mathrm{~mm}$ was selected. No pressure was applied by the probe of the muscle. Each muscle was scanned three times; hence, the mean was analyzed. All examinations were performed by a radiologist with seven years of experience in elastography. Measurements were validated using an elasticity QA Phantom model 049A (Computerized Imaging Reference Systems, Inc, Norfolk, VA, USA). Inter- and intraobserver agreements between the stiffness measurements of the masseter muscle performed using the Aixplorer Ultimate device were rated excellent and confirmed diagnostic accuracy of this method [29]; however, in this study, the calculation of the intraobserver agreement was not included.

Data were statistically analyzed with the R Project for Statistical Computing v. 3.4.1. The data were presented as means with standard deviations and medians with interquartile range (IQR). Normality was checked with the Shapiro-Wilk test; all variables except for left masseter stiffness measurement had distribution other than normal. Stiffness measurements were compared with the Wilcoxon rank-sum. Differences were considered statistically significant at $p<0.05$. The sample size calculation was based on the following assumptions: type I error $(\alpha=0.05)$, type II error $(\beta=0.10)$, the difference of means of 0.56 , standard deviations of 0.65 and an equal number of measurements in both tested groups due to comparisons between sides of the body. Such assumptions set the minimum sample size of 30 participants.

\section{Results}

The study included 30 children (12 boys and 18 girls). The range of age for girls was from 1 to 15 years and for boys, it was from 9 to 14 years. The mean age was $10.87 \pm 3.38$ years, with girls not significantly younger than boys. Stiffness for the total sample was $6.37 \pm 0.77 \mathrm{kPa}$. The detailed values of the masseter muscle stiffness are presented in Table 1.

Table 1. Age and results values of stiffness measured by shear-wave elastography.

\begin{tabular}{ccc}
\hline Group & Mean \pm SD & Median (IQR) \\
\hline Total & & \\
Age (year) & $10.87 \pm 3.38$ & $12.00(9.25-13.00)$ \\
Left masseter $(\mathrm{kPa})$ & $6.47 \pm 0.78$ & $6.33(6.11-7.04)$ \\
SD of left masseter & $1.45 \pm 0.42$ & $1.41(1.11-1.63)$ \\
Right masseter $(\mathrm{kPa})$ & $6.24 \pm 0.76$ & $6.30(5.58-6.71)$ \\
SD of right masseter & $1.41 \pm 0.52$ & $1.40(0.91-1.83)$ \\
\hline Girls & & \\
Age (year) & $10.28 \pm 4.16$ & $11.50(8.25-13.00)$ \\
Total value $(\mathrm{kPa})$ & $6.63 \pm 0.80$ & $6.68(6.10-7.13)$ \\
Left masseter $(\mathrm{kPa})$ & $6.72 \pm 0.85$ & $6.87(6.17-7.13)$ \\
SD of left masseter & $1.62 \pm 0.42$ & $1.60(1.37-1.70)$ \\
Right masseter $(\mathrm{kPa})$ & $6.54 \pm 0.77$ & $6.63(5.87-6.77)$ \\
SD of right masseter & $1.61 \pm 0.53$ & $1.73(1.00-2.03)$ \\
\hline Boys & & \\
Age (year) & $11.75 \pm 1.42$ & $12.00(11.00-13.00)$ \\
Total value $(\mathrm{kPa})$ & $5.94 \pm 0.50$ & $6.12(5.55-6.30)$ \\
Left masseter $(\mathrm{kPa})$ & $6.09 \pm 0.46$ & $6.17(6.10-6.31)$ \\
SD of left masseter & $1.20 \pm 0.30$ & $1.12(1.06-1.31)$ \\
Right masseter $(\mathrm{kPa})$ & $5.80 \pm 0.52$ & $5.67(5.50-6.30)$ \\
SD of right masseter & $1.10 \pm 0.33$ & $0.92(0.86-1.40)$ \\
\hline
\end{tabular}


Comparisons of the measurements did not show significant differences between the right and the left masseter muscles, which is shown in Table 2. However, differences could be observed between boys and girls.

Table 2. Comparison between groups.

\begin{tabular}{cc}
\hline Comparison & $p$-Value \\
\hline Age boys/age girls (year) & 0.5354 \\
Left masseter total/right masseter total & 0.3546 \\
Masseters boys/masseters girls & 0.0006 \\
Left masseter girls/right masseter girls & 0.3420 \\
Left masseter boys/right masseter boys & 0.2973 \\
Left masseter girls/left masseters boys & 0.0416 \\
Right masseter girls/right masseters boys & 0.0030 \\
\hline
\end{tabular}

Figure 1 shows an exemplary measurement of elasticity of the masseter muscle of a 12-year-old boy in which the homogenous stiffness of the masseter muscle within the box (homogenous blue color) can be seen. This image is characteristic for underage people with a mean elasticity of $5.4 \mathrm{kPa}$.

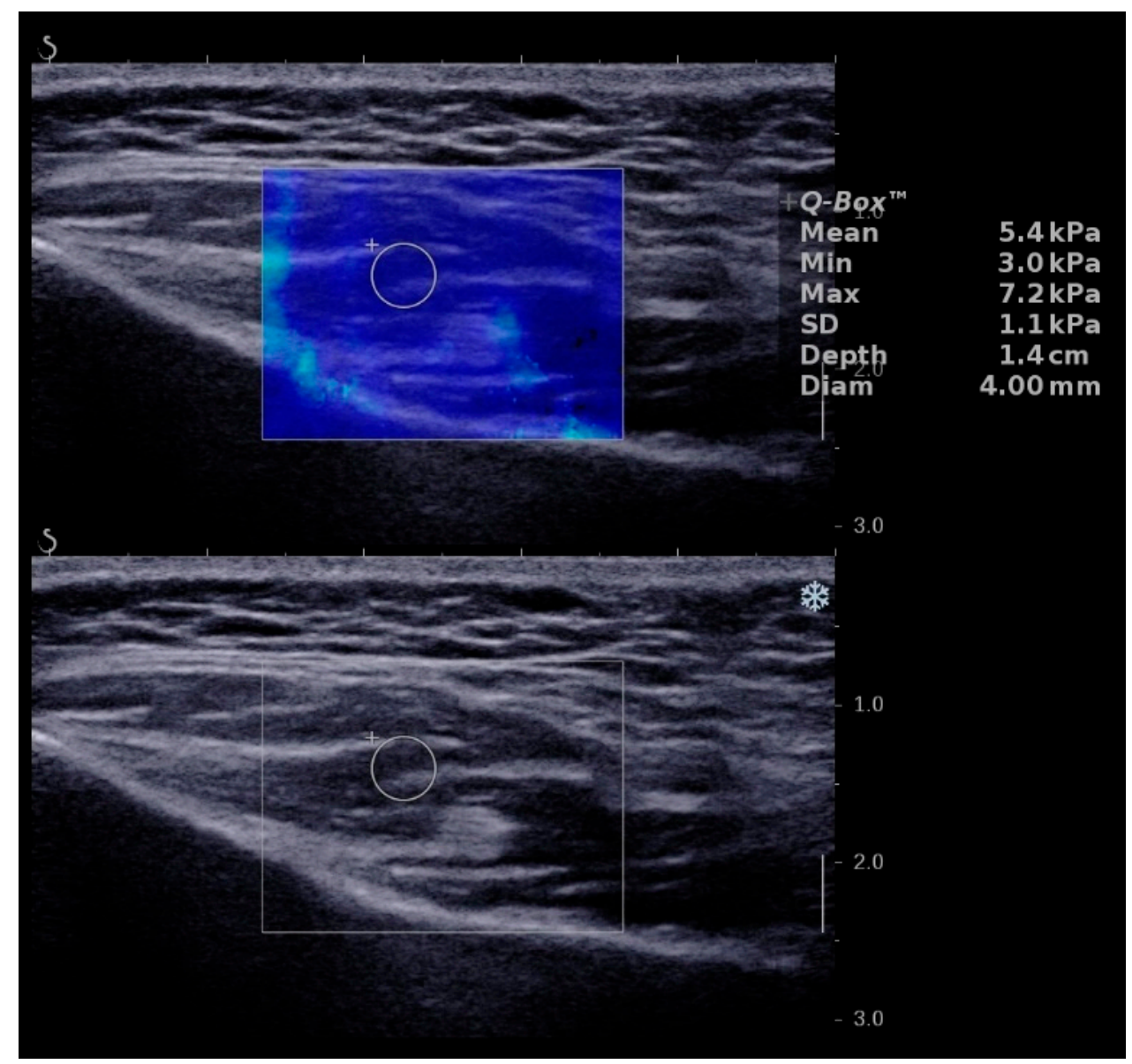

Figure 1. Elasticity of masseter muscle of a 12-year-old boy.

\section{Discussion}

The present study showed that in healthy children, the stiffness of the masseter muscle measured with shear-wave elastography was $6.37 \pm 0.77 \mathrm{kPa}$ on average. Similar values for the right and left masseter muscle, but the values in girls were higher than those recorded in boys (boys-5.94 $\pm 0.50 \mathrm{kPa}$; girls-6.63 $\pm 0.80 ; p=0.0006$ ). This study provided 
the preliminary characteristics of the small sample and, thus, further research has to be conducted to investigate masseter muscle stiffness in healthy children, including the impact of age, sex and dentition type, as well as any pathologic conditions. For this reason, our results should be interpreted with caution.

Little is known about the stiffness of the masseter muscle in the pediatric population. Up to date, only one preliminary study reported masseter muscle stiffness in healthy children and adolescents. In this study, however, the mean stiffness value was very high and amounted to $16.96 \pm 9.01 \mathrm{kPa}$ with the closed mouth [32]. Because there is no other evidence on the stiffness of the masseter muscle, we show here that every muscle has its own stiffness characteristics and requires individual reference values. Several studies examined stiffness of the gastrocnemius lateralis muscle in children with typical development. Brandenburg et al. showed that stiffness values depended on a degree of plantar flexion and ranged from $7.8 \mathrm{kPa}$ (IQR: 6.1,11.0) for 20 degrees to $14.9 \mathrm{kPa}$ (IQR: 10.9, 20.9) when the foot was in a natural position without any flexion. Their study included 13 children with a median age of median age 5 years and 3 months [25]. Lacourpaille et al. measured stiffness for six muscles and recorded the results at two muscle lengths (shortened and stretched). In their study, the mean age of the healthy control group $(n=13)$ was $12.86 \pm 5.5$ years. The following mean values for two muscle positions were given: for the tibialis anterior muscle $-7.0 \pm 1.9 \mathrm{kPa}$ and $12.5 \pm 3.1 \mathrm{kPa}$; for the gastrocnemius medialis muscle $-4.9 \pm 0.9 \mathrm{kPa}$ and $14.5 \pm 3.4 \mathrm{kPa}$; for the vastus lateralis muscle $-5.4 \pm 1.7 \mathrm{kPa}$ and $9.6 \pm 2.2 \mathrm{kPa}$; for the biceps brachii-3.9 $\pm 0.4 \mathrm{kPa}$ and $18.9 \pm 6.4 \mathrm{kPa}$; for the triceps brachii- $-5.0 \pm 0.9 \mathrm{kPa}$ and $7.3 \pm 1.4 \mathrm{kPa}$; and for the abductor digiti minimi-7.5 $\pm 2.2 \mathrm{kPa}$ and $11.9 \pm 5.0 \mathrm{kPa}$ [33]. Another study by Lacourpaille et al. showed that values of muscle stiffness measured in 5 muscles were comparable over a 12-month follow-up in the control group $(n=9)$ but differed for some muscles in children with Duchenne muscular dystrophy $(n=10)$ [26]. The assessment of lateral abdominal muscles in children with scoliosis was carried out by Linek et al. [27]. In a supine rest position, the following values were reported: for the external oblique muscle-21.1 $\pm 9.19 \mathrm{kPa}$ on the right side and $18.8 \pm 7.34 \mathrm{kPa}$ on the left side; for the internal oblique muscle- $-14.6 \pm 4.24 \mathrm{kPa}$ on the right side and $13.4 \pm 4.54 \mathrm{kPa}$; and for the transversus abdominis muscle-13.8 $\pm 4.22 \mathrm{kPa}$ on the right side and $11.5 \pm 3.76 \mathrm{kPa}$ on the left side. The study group included 35 children aged $12.8 \pm 2.8$ years on average. Although the groups in those studies were small, it can be observed that each muscle has its unique range of stiffness values. For this reason, there is a need to characterize each of the muscles separately and provide values for the healthy muscle and each pathological condition individually. There is also a need to investigate factors influencing muscle stiffness such as age, treatments or exercise because such factors were proved to change masseter muscle stiffness in adults [34,35].

A systematic review by Olchowy et al. showed that stiffness depends not only on the type of the muscle but also on the device that was used for measurements [36]. Regarding the masseter muscle, several studies reported stiffness of this muscle; however, all were conducted in the adult cohorts. Three of the studies used the Aixplorer device, the same as we did for our measurements. Arda et al. examined 127 healthy volunteers; the average stiffness of the masseter muscle in this group was $10.4 \pm 3.7 \mathrm{kPa}$ [37]. In the study conducted by Herman et al., the mean stiffness of the masseter muscle in 176 healthy volunteers was $10.0 \pm 4.3 \mathrm{kPa}$ [38]. The study by Olchowy et al. conducted on 140 healthy adults determined the elasticity to be $10.67 \pm 1.77 \mathrm{kPa}$ [39]. The average value obtained in the pediatric population in the present study was $6.37 \pm 0.77 \mathrm{kPa}$, which was about one third less than in adults. The reason for higher stiffness in adults is the fact that stiffness increases with age due to muscular atrophy and a change in fibre composition and distribution and the muscle-tendon complex $[40,41]$. We can therefore conclude that stiffness of the masseter muscle in children is lower than in adults. Chodock et al. using the Aixplorer ultrasound device found that age was a significant predictor of a mean shearwave velocity only for the muscles of the sternocostal region of the pectoralis major and the middle trapezius, but not for the anterior deltoid, biceps brachii and the muscles of the 
clavicular region [42]. Differences in muscle tonus were also confirmed by other methods such as myotonometry. Dietsch et al. investigated tissue stiffness using myotonometry in 40 healthy adults aged from 18 to 90 years old. They found that values of stiffness were significantly higher in older participants aged from 61 to 90 years old in comparison to younger ones aged from 22 to 37 years old [14]. In contrast, Sendur et al. found that stiffness of the gastrocnemius muscle decreased with age in a group of 57 healthy participants aged 18 to 74 years [43]. These conflicting results add another reason for the need to characterise each muscle separately. Olchowy et al. reported that stiffness increased after a massage session [34].

The muscle stiffness difference described between children and adults is especially interesting in the context of the prevalence of muscle disorders, particularly masticatory muscles disorders. As mentioned in the introduction, TMD seems to increase with age and thus affect adults more frequently than children and adolescents. While the prevalence of TMD in adults is reported to affect 55.9\% [9], the highest prevalence of TMD reported in adolescents was 33\% [12]. As reported in the previous studies, the stiffness of masseter muscles seems to be higher in individuals presenting masticatory myofascial pain than in healthy controls. As also previously mentioned, general muscle stiffness was reported to increase with age [44] and one of the most common TMD symptoms is increased muscle tension and pain [45]. This information leads to the hypothesis that lower basial stiffness of masticatory muscles in children and adolescents can be possibly associated with higher masticatory muscles adaptation ability and the lower muscle-origin TMD prevalence. However, this topic requires further research.

\section{Conclusions}

Shear-wave elastography is a promising diagnostic tool. It may help to detect changes in stiffness of the masseter muscle and draws attention to pathological processes within the jaw muscles. Directions for further research shall include further determination of stiffness values in pathological conditions and the impact of biological and functional factors on the stiffness of the masseter muscle.

Author Contributions: Conceptualization, C.O., A.O. and L.M.S.; Data curation, C.O. and A.O.; Formal analysis, C.O. and A.P.; Investigation, C.O. and A.O.; Methodology, C.O., A.O., M.W. and L.M.S.; Resources, C.O.; Supervision, C.O. and A.O.; Visualization, C.O.; Writing-original draft, A.O. and A.P.; Writing-review a d editing, C.O., M.W. and L.M.S. All authors have read and agreed to the published version of the manuscript.

Funding: This research received no external funding.

Institutional Review Board Statement: The study was approved by the Bioethical Committee at the Wroclaw Medical University (KB-633/2020). The study was conducted in accordance with the Declaration of Helsinki and Good Clinical Practice.

Informed Consent Statement: Parents were asked for written informed consent for the participation of their child in the study. All children gave their consent for participation in the study as well.

Data Availability Statement: The data presented in this study are openly available in FigShare at doi:10.6084/m9.figshare.16608619.

Conflicts of Interest: The authors declare no conflict of interest.

\section{References}

1. Bertini, E.; D’Amico, A.; Gualandi, F.; Petrini, S. Congenital muscular dystrophies: A brief review. Semin. Pediatr. Neurol. 2011, 18, 277-288. [CrossRef]

2. Kruse, A.; Schranz, C.; Tilp, M.; Svehlik, M. Muscle and tendon morphology alterations in children and adolescents with mild forms of spastic cerebral palsy. BMC Pediatr. 2018, 18, 156. [CrossRef]

3. Hemke, R.; Herregods, N.; Jaremko, J.L.; Åström, G.; Avenarius, D.; Becce, F.; Bielecki, D.K.; Boesen, M.; Dalili, D.; Giraudo, C.; et al. Imaging assessment of children presenting with suspected or known juvenile idiopathic arthritis: ESSR-ESPR points to consider. Eur. Radiol. 2020, 30, 5237. [CrossRef] 
4. Parent, S.; Mac-Thiong, J.M.; Roy-Beaudry, M.; Sosa, J.F.; Labelle, H. Spinal cord injury in the pediatric population: A systematic review of the literature. J. Neurotrauma 2011, 28, 1515-1524. [CrossRef]

5. Wahlund, K. Temporomandibular disorders in adolescents. Epidemiological and methodological studies and a randomized controlled trial. Swed. Dent. J. Suppl. 2003, 164, 2-64.

6. Goo, M.; Johnston, L.M.; Hug, F.; Tucker, K. Systematic Review of Instrumented Measures of Skeletal Muscle Mechanical Properties: Evidence for the Application of Shear Wave Elastography with Children. Ultrasound Med. Biol. 2020, 46, 1831-1840. [CrossRef]

7. Al-Khotani, A.; Naimi-Akbar, A.; Gjelset, M.; Albadawi, E.; Bello, L.; Hedenberg-Magnusson, B.; Christidis, N. The associations between psychosocial aspects and TMD-pain related aspects in children and adolescents. J. Headache Pain 2016, 17, 30. [CrossRef] [PubMed]

8. Christidis, N.; Lindström Ndanshau, E.; Sandberg, A.; Tsilingaridis, G. Prevalence and treatment strategies regarding temporomandibular disorders in children and adolescents-A systematic review. J. Oral Rehabil. 2019, 46, 291-301. [CrossRef] [PubMed]

9. Wieckiewicz, M.; Grychowska, N.; Nahajowski, M.; Hnitecka, S.; Kempiak, K.; Charemska, K.; Balicz, A.; Chirkowska, A.; Zietek, M.; Winocur, E. Prevalence and Overlaps of Headaches and Pain-Related Temporomandibular Disorders Among the Polish Urban Population. J. Oral Facial Pain Headache 2020, 34, 31-39. [CrossRef] [PubMed]

10. List, T.; Wahlund, K.; Wenneberg, B.; Dworkin, S.F. TMD in children and adolescents: Prevalence of pain, gender differences, and perceived treatment need. J. Orofac. Pain 1999, 13, 9-20.

11. Franco-Micheloni, A.L.; Fernandes, G.; de Godoi Gonçalves, D.A.; Camparis, C.M. Temporomandibular Disorders in a Young Adolescent Brazilian Population: Epidemiologic Characterization and Associated Factors. J. Oral Facial Pain Headache 2015, 29, 242-249. [CrossRef] [PubMed]

12. De Melo Júnior, P.C.; Aroucha, J.; Arnaud, M.; Lima, M.G.S.; Gomes, S.G.F.; Ximenes, R.; Rosenblatt, A.; Caldas, A.F., Jr. Prevalence of TMD and level of chronic pain in a group of Brazilian adolescents. PLoS ONE 2019, 14, e0205874. [CrossRef] [PubMed]

13. Scrivani, S.J.; Khawaja, S.N.; Bavia, P.F. Nonsurgical Management of Pediatric Temporomandibular Joint Dysfunction. Oral Maxillofac. Surg. Clin. N. Am. 2018, 30, 35-45. [CrossRef]

14. Dietsch, A.M.; Clark, H.M.; Steiner, J.N.; Solomon, N.P. Effects of Age, Sex, and Body Position on Orofacial Muscle Tone in Healthy Adults. J. Speech Lang. Hear. Res. 2015, 58, 1145-1150. [CrossRef]

15. Carroll, K.; Yiu, E.M.; Ryan, M.M.; Kennedy, R.A.; de Valle, K. The effects of calf massage in boys with Duchenne muscular dystrophy: A prospective interventional study. Disabil. Rehabil. 2020, 1-7. [CrossRef]

16. Gagnat, Y.; Brændvik, S.M.; Roeleveld, K. Surface Electromyography Normalization Affects the Interpretation of Muscle Activity and Coactivation in Children With Cerebral Palsy During Walking. Front. Neurol. 2020, 11, 202. [CrossRef] [PubMed]

17. Díaz-Serrano, K.V.; Dias, T.M.; Vasconcelos, P.; Sousa, L.G.; Siéssere, S.; Regalo, S.; Palinkas, M. Impact of temporomandibular disorders on the stomatognathic system in children. Med. Oral Patol. Oral Cir. Bucal. 2017, 22, e723-e729. [CrossRef] [PubMed]

18. Bohannon, R.W.; Smith, M.B. Interrater reliability of a modified Ashworth scale of muscle spasticity. Phys. Ther. 1987, 67, 206-207. [CrossRef] [PubMed]

19. Akbaş, A.N. Assessments and outcome measures of cerebral palsy. In Cerebral Palsy-Current Steps; Gunel, M.K., Ed.; IntechOpen: London, UK, 2016.

20. Ariji, Y.; Nakayama, M.; Nishiyama, W.; Ogi, N.; Sakuma, S.; Katsumata, A.; Kurita, K.; Ariji, E. Can sonographic features be efficacy predictors of robotic massage treatment for masseter and temporal muscle in patients with temporomandibular disorder with myofascial pain? Cranio 2016, 34, 13-19. [CrossRef]

21. Kishimoto, R.; Suga, M.; Koyama, A.; Omatsu, T.; Tachibana, Y.; Ebner, D.K.; Obata, T. Measuring shear-wave speed with point shear-wave elastography and MR elastography: A phantom study. BMJ Open 2017, 7, e013925. [CrossRef]

22. Calvete, A.C.; Rodriguez, J.M.; de Dios Berna-Mestre, J.; Rios, A.; Abellan-Rivero, D.; Reus, M. Interobserver agreement for thyroid elastography: Value of the quality factor. J. Ultrasound Med. 2013, 32, 495-504. [CrossRef]

23. Garcovich, M.; Di Stasio, E.; Zocco, M.A.; Riccardi, L.; Elena Ainora, M.; Annicchiarico, B.E.; Gibiino, G.; Santopaolo, F.; Gasbarrini, A.; Pompili, M. Assessing Baveno VI criteria with liver stiffness measured using a new point-shear wave elastography technique (BAVElastPQ study). Liver Int. 2020, 40, 1952-1960. [CrossRef]

24. Xu, B.; Jiang, G.; Ye, J.; He, J.; Xie, W. Research on pediatric glomerular disease and normal kidney with shear wave based elastography point quantification. JPN J. Radiol. 2016, 34, 738-746. [CrossRef]

25. Brandenburg, J.E.; Eby, S.F.; Song, P.; Kingsley-Berg, S.; Bamlet, W.; Sieck, G.C.; An, K.-N. Quantifying passive muscle stiffness in children with and without cerebral palsy using ultrasound shear wave elastography. Dev. Med. Child. Neurol. 2016, 58, 1288-1294. [CrossRef]

26. Lacourpaille, L.; Gross, R.; Hug, F.; Guével, A.; Péréon, Y.; Magot, A.; Hogrel, J.-Y.; Nordez, A. Effects of Duchenne muscular dystrophy on muscle stiffness and response to electrically-induced muscle contraction: A 12-month follow-up. Neuromuscul. Disord. 2017, 27, 214-220. [CrossRef] [PubMed]

27. Linek, P.; Wolny, T.; Sikora, D.; Klepek, A. Supersonic Shear Imaging for Quantification of Lateral Abdominal Muscle Shear Modulus in Pediatric Population with Scoliosis: A Reliability and Agreement Study. Ultrasound Med. Biol. 2019, 45, 1551-1561. [CrossRef] 
28. Thomas, K.; Shankar, H. Targeting myofascial taut bands by ultrasound. Curr. Pain Headache Rep. 2013, 17, 349. [CrossRef] [PubMed]

29. Olchowy, C.; Olchowy, A.; Hadzik, J.; Dabrowski, P.; Mierzwa, D. Dentists can provide reliable shear wave elastography measurements of the stiffness of masseter muscles: A possible scenario for a faster diagnostic process. Adv. Clin. Exp. Med. 2021, 30, 575-580. [CrossRef] [PubMed]

30. Raadsheer, M.C.; Van Eijden, T.M.; Van Spronsen, P.H.; Van Ginkel, F.C.; Kiliaridis, S.; Prahl-Andersen, B. A comparison of human masseter muscle thickness measured by ultrasonography and magnetic resonance imaging. Arch. Oral Biol. 1994, 39, 1079-1084. [CrossRef]

31. Botticchio, A.; Mourad, F.; Fernández-Carnero, S.; Arias-Buría, J.L.; Santodomingo Bueno, A.; Mesa Jiménez, J.; Gobbo, M. Short-Term Morphological Changes in Asymptomatic Perimandibular Muscles after Dry Needling Assessed with Rehabilitative Ultrasound Imaging: A Proof-of-Concept Study. J. Clin. Med. 2021, 10, 209. [CrossRef]

32. Öztürk, M.; Çalışkan, E.; Habibi, H.A. Shear wave elastography of temporomandibular joint disc and masseter muscle stiffness in healthy children and adolescents: A preliminary study. Oral Radiol. 2021. [CrossRef]

33. Lacourpaille, L.; Hug, F.; Guével, A.; Péréon, Y.; Magot, A.; Hogrel, J.-Y.; Nordez, A. Non-invasive assessment of muscle stiffness in patients with duchenne muscular dystrophy. Muscle Nerve 2015, 51, 284-286. [CrossRef]

34. Olchowy, C.; Więckiewicz, M.; Sconfienza, L.M.; Łasecki, M.; Seweryn, P.; Smardz, J.; Hnitecka, S.; Dominiak, M.; Olchowy, A. Potential of Using Shear Wave Elastography in the Clinical Evaluation and Monitoring of Changes in Masseter Muscle Stiffness. Pain Res. Manag. 2020, 2020, 4184268. [CrossRef]

35. Olchowy, C.; Grzech-Leśniak, K.; Hadzik, J.; Olchowy, A.; Łasecki, M. Monitoring of Changes in Masticatory Muscle Stiffness after Gum Chewing Using Shear Wave Elastography. J. Clin. Med. 2021, 10, 2480. [CrossRef] [PubMed]

36. Olchowy, A.; Wieckiewicz, M.; Winocur, E.; Dominiak, M.; Dekkers, I.; Łasecki, M.; Olchowy, C. Great potential of ultrasound elastography for the assessment of the masseter muscle in patients with temporomandibular disorders. A systematic review. Dentomaxillofac. Radiol. 2020, 49, 20200024. [CrossRef]

37. Arda, K.; Ciledag, N.; Aktas, E.; Aribas, B.K.; Kose, K. Quantitative assessment of normal soft-tissue elasticity using shear-wave ultrasound elastography. AJR Am. J. Roentgenol. 2011, 197, 532-536. [CrossRef]

38. Herman, J.; Sedlackova, Z.; Vachutka, J.; Furst, T.; Salzman, R.; Vomacka, J. Shear wave elastography parameters of normal soft tissues of the neck. Biomed. Pap. Med. Fac. Univ. Palacky Olomouc. Czech Repub. 2017, 161, 320-325. [CrossRef]

39. Olchowy, A.; Więckiewicz, M.; Malysa, A.; Olchowy, C. Determination of Reference Values of the Masseter Muscle Stiffness in Healthy Adults Using Shear Wave Elastography. Int. J. Environ. Res. Public Health 2021, 18, 9371. [CrossRef] [PubMed]

40. Pavan, P.; Monti, E.; Bondí, M.; Fan, C.; Stecco, C.; Narici, M.; Reggiani, C.; Marcucci, L. Alterations of Extracellular Matrix Mechanical Properties Contribute to Age-Related Functional Impairment of Human Skeletal Muscles. Int. J. Mol. Sci. 2020, 21, 3992. [CrossRef]

41. Ochala, J.; Lambertz, D.; Pousson, M.; Goubel, F.; Hoecke, J.V. Changes in mechanical properties of human plantar flexor muscles in ageing. Exp. Gerontol. 2004, 39, 349-358. [CrossRef] [PubMed]

42. Chodock, E.; Hahn, J.; Setlock, C.A.; Lipps, D.B. Identifying predictors of upper extremity muscle elasticity with healthy aging. J. Biomech. 2020, 103, 109687. [CrossRef] [PubMed]

43. Şendur, H.N.; Cindil, E.; Cerit, M.N.; Kılıç, P.; Gültekin, I.; Oktar, S. Evaluation of effects of aging on skeletal muscle elasticity using shear wave elastography. Eur. J. Radiol. 2020, 128, 109038. [CrossRef] [PubMed]

44. Takashima, M.; Arai, Y.; Kawamura, A.; Hayashi, T.; Takagi, R. Quantitative evaluation of masseter muscle stiffness in patients with temporomandibular disorders using shear wave elastography. J. Prosthodont. Res. 2017, 61, 432-438. [CrossRef] [PubMed]

45. Perez, C. Temporomandibular disorders in children and adolescents. Gen. Dent. 2018, 66, 51-55. 